\title{
Aprendendo IHC em Instituições, Áreas e Países: Um Estudo de Campo de Estilos Cognitivos em Tarefas Analíticas e Criativas
}

\author{
José Abdelnour-Nocera \\ Madeira Interactive \\ Technologies Institute \\ Funchal, Portugal \\ University of West London, \\ London, United Kingdom \\ Jose.Abdelnour- \\ Nocera@uwl.ac.uk
}

\author{
Torkil Clemmensen \\ Copenhagen Business School \\ Frederiksberg, Denmark \\ tc.itm@cbs.dk
}

\author{
Tatiane G. Guimarães \\ Universidade Federal de Minas \\ Gerais \\ Belo Horizonte, Brazil \\ tatiguimaraes@dcc.ufmg.br
}

\begin{abstract}
INTRODUÇÃO
Interação Humano-Computador (IHC) é uma área do conhecimento diversa em termos de países, instituições, departamentos e cursos em que é oferecida; e também em termos de pessoas que são ou estão se tornando pesquisadores e profissionais na área. A diversidade de contextos, conteúdos, e estilos de aprendizado dos estudantes são alguns dos fatores que trazem desafios para o ensino de IHC. Este estudo procura contribuir para o entendimento da interação entre o currículo de IHC e estudantes em diferentes instituições, áreas do conhecimento e países através da exploração da interação entre o currículo de IHC e estudantes de contextos distintos.
\end{abstract}

\section{TRABALHOS RELACIONADOS}

\section{Ensino de IHC}

Existem trabalhos sobre o Ensino de IHC em vários contextos. Enquanto em alguns IHC é considerada um tópico essencial, em outros é considerada um conteúdo supérfulo. Fatores que influenciam nesta questão vão desde políticas nacionais até a cultura institucional de onde IHC é ofertada.

O desenvolvimento de comunidades de IHC tem um papel fundamental para o fortalecimento da área em uma região ou instituição. Dadas características de cada contexto, pesquisas recentes mostram que comunidades de IHC precisam de um espaço para compartilhar recursos e experiências relacionadas ao ensino de IHC, e que diferenças contextuais e regionais devem ser consideradas no currículo de IHC. Sendo assim, o currículo deve ser flexível e diverso, oferecendo conteúdo relevante para os estudantes [2].

Permission to make digital or hard copies of all or part of this work for personal or classroom use is granted without fee provided that copies are not made or distributed for profit or commercial advantage and that copies bear this notice and the full citation on the first page. Copyrights for components of this work owned by others than the author(s) must be honored. Abstracting with credit is permitted. To copy otherwise, or republish, to post on servers or to redistribute to lists, requires prior specific permission and/or a fee. Copyright 2018 SBC

IHC 2018, Anais Estendidos do XVII Simpósio Brasileiro sobre Fatores Humanos em Sistemas Computacionais

Outubro 22-26, 2018, Belém, Brasil

Artigos Internacionais

\section{Estilos Cognitivos}

A relação entre cultura, aprendizado e estilos cognitivos é bem estabelecida. Posições culturais, por exemplo, influenciam o raciocínio holístico e analítico [5]. Raciocínio holístico indica uma orientação ao contexto como um todo. Raciocínio analítico indica uma tendência a isolar o objeto do seu contexto na busca de relações causais. Pesquisas na área levaram ao desenvolvimento do Índice de Estilo Cognitivo (Cognitive Style Index - CSI) [1] - um questionário compacto projetado para testar a tendência a uma abordagem intuitiva ou analítica. A pontuação no CSI abrange as seguintes faixas de estilos cognitivos: Intuitivo (0-28), Quasi-Intuitivo (29 - 38), Adaptativo (39 - 45), Quasi-Analítico (46 - 52) e Analítico (53 - 76).

Tarefas predominantemente analíticas ou criativas podem exigir diferentes habilidades e estilos de pensamento de profissionais de IHC. Para tarefas analíticas, como avaliação de usabilidade, sabe-se que o estilo cognitivo tem um impacto e pode variar em diferentes culturas [3]. Para tarefas criativas, como a criação de personas, existem indícios de pesquisas com outros profissionais de que pessoas na função de design apresentam tendências de introversão e intuição [4].

\section{METODOLOGIA}

Este trabalho incluiu visitas a grupos de estudantes em instituições e países diferentes (Reino Unido, Índia, Namíbia, México e China). Em cada grupo, entre 18 e 22 estudantes foram convidados a completar o questionário de CSI e participar de um workshop. O workshop foi estruturado incluindo uma breve explicação sobre avaliação heurística e personas; seguido da apresentação do portal a ser avaliado, cenários para a inspeção e criação de personas; e debriefing.

A performance dos estudantes no workshop foi analisada e correlacionada com os resultados dos perfis cognitivos segundo o CSI. Para isso, as respostas foram quantificadas com relação à sua riqueza. Para a avaliação heurística cada resposta foi pontuada de zero a três, sendo zero atribuído a respostas sem justificativas e três para justificativas com referências claras a aspectos de design do portal avaliado. Para a criação de personas, foi quantificado o número de características descritas. 


\section{RESULTADOS E DISCUSSÃO}

A pontuação média entre os cem estudantes que completaram o questionário foi de 42.51, caindo claramente na faixa Adaptativa. Isso reforça a expectativa de que profissionais de IHC precisam ser capazes de equilibrar habilidades intuitivas e analíticas para resolver problemas e criar boas soluções.

A variância entre os grupos pode ser comparada e nenhuma diferença significativa entre perfis para cada grupo foi encontrada. No entanto, enquanto China, México, Namíbia e Reino Unido tiveram entre 70-79\% dos estudantes nas faixas Quasi-Intuitiva, Adaptativa e Quasi-Analítica, na Índia 95\% dos estudantes encontram-se nestas faixas. Esta concentração pode estar relacionada à seleção dos estudantes. Para ingressar no curso de Design, os estudantes participaram de um processo seletivo baseado em matemática e algoritmos. Este filtro pode admitir estudantes analíticos com aptitude para design, o que em termos do CSI significa estudantes Adaptativos.

Dos cem alunos que responderam o questionário, 61 completaram a tarefa da avaliação heurística. Considerando-se a performance de todos os grupos, existe uma correlação positiva entre a pontuação no CSI e a performance na avaliação heuríscia, que é fundamentalmente uma tarefa analítica. Ou seja, quanto mais analítico o perfil cognitivo do estudante, maior a probabilidade de ele produzir uma análise mais rica. Isso indica que tarefas analíticas de IHC podem ser sensíveis a estudantes com estilos cognitivos congruentes.

Dos 61 estudantes que completaram a tarefa de avaliação heurística, 53 completaram a tarefa de criação de personas. Não foi encontrada correlação entre a pontuação no CSI e a performance nesta tarefa - ao contrário do esperado de que estudantes com estilo mais intuitivo produziriam personas mais ricas. Em retrospectiva, nas instituições em que a relação entre estudantes e tutores era hierárquica, nossa avialiação pode não ter medido o nível de empatia dos estudantes, mas sim a sua capacidade de seguir as instruções dos instrutores sobre a aplicação sistemática e analítica do método.

Foram encontradas diferenças significativas na performance de grupos diferentes.Na tarefa da avaliação heurística, existe uma diferença significativa entre o grupo da Índia e os grupos do Reino Unido e Namíbia. Na tarefa da criação de personas, existe uma diferença significativa entre a China e Namíbia, que são os grupos com melhor e pior performance respectivamente. O grupo da Namíbia tem a menor média de CSI, estando no limite superior da faixa Quasi-Intuitiva e produziu o menor número de características nas personas criadas. Isto pode ser relacionado a traços culturais coletivistas da região [6].

De maneira geral, o valor dado à IHC dentro da instituição é sujeito à cultura dos cursos nos quais estavam inseridos (por exemplo cursos de design, administração ou computação) e à existência de pessoas em posições de decisão interessadas em garantir que IHC fosse oferecida no nível de graduação.

Os resultados sugerem que o ensino de IHC enfrenta dois grandes desafios: (1) apoiar estilos cognitivos necessários para aprender e fazer IHC; e (2) apoiar a crescente diversidade no ensino, localização e valorização do currículo de IHC, incluindo IHC em diferentes áreas do conhecimento.
Quanto ao primeiro, nossos resultados sugerem que devemos promover a tolerância com relação a estilos analíticos e intuitivos em sala de aula. Devemos pensar nos estudantes como designers criativos que devem ser encorajados a desenvolver ambos os tipos de pensamento. Não é claro, no entanto, como apoiar o estilo intuitivo, ou como tornar os estudantes mais adaptativos ao invés de puramente analíticos. Uma maneira que observamos que isto poderia ser feito é através do recrutamento e seleção, como no caso da Índia discutido acima.

Quanto ao segundo, encontramos diversas diferenças no ensino de IHC entre as instituições, áreas do conhecimento e países neste estudo. Estes resultados implicam que devemos apoiar a diversidade no ensino, localização e valorização do currículo de IHC. Isto já foi levantado pela literatura (ex. [2]). É importante ressaltar que a promoção de comunidades de IHC é de extrema importância para o crescimento da área.

\section{CONSIDERAÇÕES FINAIS}

O objetivo deste estudo foi explorar interações entre o currículo de IHC e estudantes de diferentes instituições e áreas do conhecimento internacionalmente. Com isto, contribuímos para a compreensão da diversidade no ensino de IHC. Este trabalho focou na relação entre estilos cognitivos como um constructo cultural e de aprendizado e como estudantes de graduação interagem com tarefas analíticas e criativas.

Foi confirmado empiricamente que estudantes de IHC tendem a mostrar estilos cognitivos Adaptativos. Além disso, existe uma correlação entre estilos cognitivos e performance na tarefa de avaliação heurística. Foram encontradas diferencas entre a performance de grupos em ambas as tarefas. Finalmente, foram feitas observações interessantes sobre a influência de fatores culturais a níveis nacionais, institucionais, e de áreas do conhecimento.

\section{REFERÊNCIAS}

1. Christopher W. Allinson and John Hayes. 1996. The Cognitive Style Index: A Measure of Intuition-Analysis For Organizational Research. Journal of Management Studies 33, 1 (Jan. 1996), 119-135.

2. Elizabeth F. Churchill, Anne Bowser, and Jennifer Preece. 2016. The Future of HCI Education: A Flexible, Global, Living Curriculum. interactions 23, 2 (Feb. 2016), 70-73.

3. Torkil Clemmensen, Morten Hertzum, Kasper Hornbæk, Qingxin Shi, and Pradeep Yammiyavar. 2009. Cultural cognition in usability evaluation. Interacting with Computers 21, 3 (July 2009), 212-220.

4. Shirley Cruz, Fabio Q. B. da Silva, and Luiz Fernando Capretz. 2015. Forty years of research on personality in software engineering. Computers in Human Behavior 46 (May 2015), 94-113.

5. Richard E. Nisbett and Yuri Miyamoto. 2005. The influence of culture: holistic versus analytic perception. Trends in Cognitive Sciences 9, 10 (Oct. 2005), 467-473.

6. Heike Winschiers-Theophilus and Nicola J. Bidwell. 2013. Toward an Afro-Centric Indigenous HCI Paradigm. Int J Hum-Comput Int 29, 4 (March 2013), 243-255. 